\title{
Methane-air-premixed flames impinging on plane surfaces
}

\author{
SATYANANDA TRIPATHY ${ }^{1}$, MANMATHA K ROUL ${ }^{2, *(0)}$ and AKSHAYA K ROUT ${ }^{1}$ \\ ${ }^{1}$ School of Mechanical Engineering, KIIT University, Bhubaneswar 751024, India \\ ${ }^{2}$ Department of Mechanical Engineering, GITA, Bhubaneswar 752054, India \\ e-mail:mkroul@gmail.com
}

MS received 23 August 2018; revised 20 June 2019; accepted 22 July 2019

\begin{abstract}
Determination of heat transfer characteristic has been analysed theoretically using the heat propagation phenomena of methane-air-premixed turbulent flames impinging on plane surfaces. The heat flux propagation on the plane surface completely depends on the distance between the plate and nozzle, Reynolds number and equivalence ratio (ER). The solution of the differential equation related to conservation of momentum, mass and energy has been analysed. The radiative heat transfer model has been designed using several radiation models and the turbulence model is analysed by the help of RNG $k-\varepsilon$ turbulence model. In the response plot it is found that heat flux increases progressively with the radial distance towards the centre of the plate to achieve the maximum value at a position a bit away from stagnation point and thereafter it reduces. It has also been exhibited that when the distance of the target plate increases, the location of the maximum value of the local heat flux approaches the stagnation point. The dependence of heat transfer phenomena on ER, Reynolds number and separation of the plate from the nozzle has been studied.
\end{abstract}

Keywords. Premixed flame; heat transfer; Reynolds number; plate separation distance; equivalence ratio.

\section{Introduction}

The use of jet flames has been found in several industries to achieve better heat transfer coefficient and to produce high rates of heat transfer. Heating by flames in industrial furnaces is employed to increase heat flux and thereby reduce fuel consumption significantly. They include melting of scrap materials, the formation of glasses, the heating of boiler furnaces and the heating of metal billets, among many more. The lack of uniformity of heat flow near the stagnation point is a major drawback of the flame impingement heating process. The heat transfer caused by the flame depends on the flame configuration, the temperature profile near the target plate, and the convection and radiation properties of the components.

The flame temperature depends on structure of impinging jet, which includes wall jet, free jet and stagnation region as shown in figure 1. Interaction of the flame jet with ambient air at exit of the nozzle results in the growth of a nonuniform velocity profile in free-jet region. In the stagnation region the static pressure is more than the ambient pressure, as a result of which the pressure gradients in stagnation region suppress the flow in axial direction and hence the flame turns radially outward. The wall jet region is free from mean pressure gradient.

*For correspondence

Published online: 19 August 2019
Many research works done in the field of heat transfer due to impinging flames are experimental in nature. Baukal and Gebhart [1] reported that the plate surface heat flux distribution due to flame impingement is non-uniform and the maximum value of heat flux was found to occur not exactly at the stagnation point but a little away from it. Boke et al [2] studied both experimentally and theoretically the heat transfer phenomena using $k-\varepsilon$ turbulence model for modelling the turbulence phenomena in combustor. For modelling the radiative heat transfer they have used the discrete ordinates (DO) radiation model. Chander and Ray [3] observed that when the length of the inner zone is less as compared with distance of the target plate from the nozzle, the peak heat flux increases when Reynolds number increases. Cornaro et al [4] observed that most of the studies using impinging flames are carried out for flat surfaces and effects of surface curvature of the target plate on heat transfer phenomena have not been investigated at all. Dong et al [5] proposed correlation for Nusselt number as a function of different geometrical and operational parameters. Hou and Ko [6] investigated heat transfer due to impinging flames on inclined plates and observed that the plate temperature and efficiency depend strongly on the distance of target plate from the nozzle and the angle of inclination of the target plate. For lower heating heights, the flame structure is strongly influenced by the angle of inclination of the target plate and for higher heating heights this influence is negligible. 


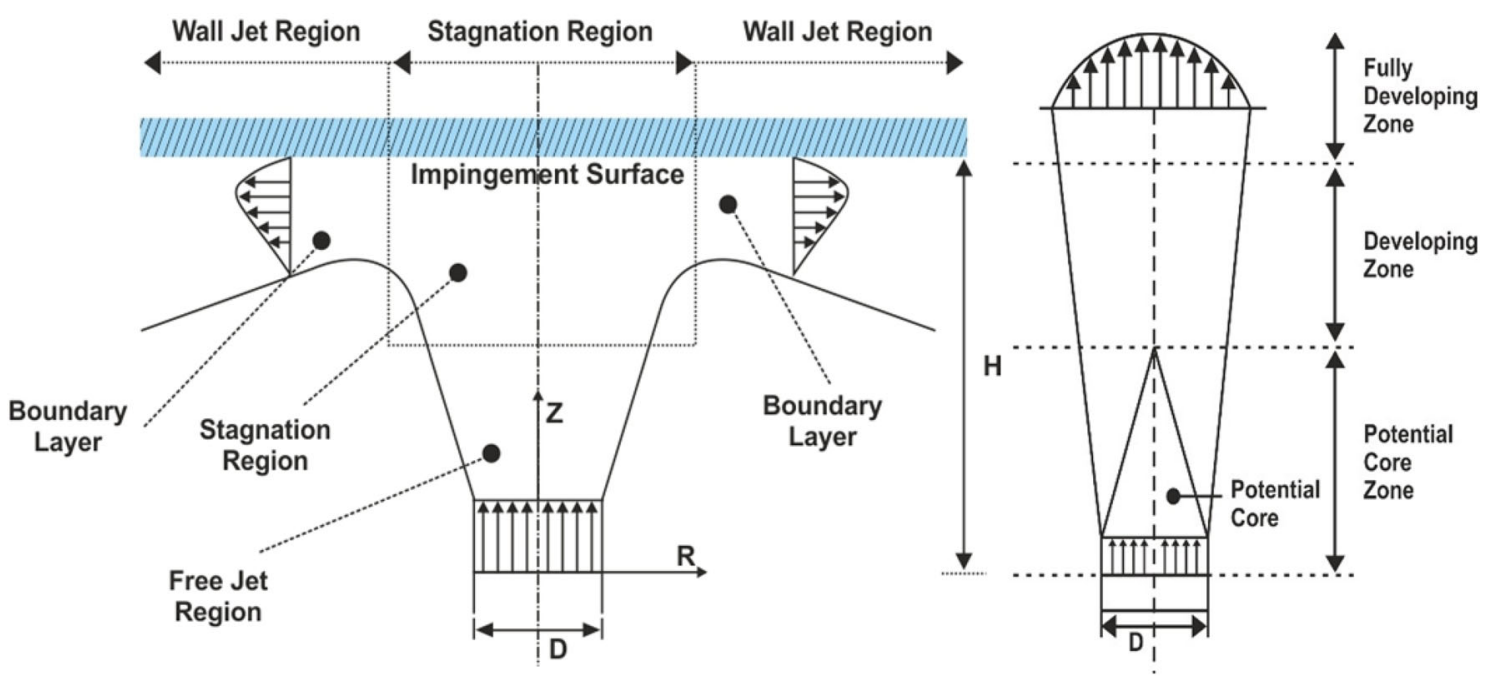

Figure 1. Schematic diagram of flame impingement heat transfer.

Kuntikana and Prabhu [7] compared the heat transfer phenomena of premixed flame jets and isothermal air jets to variation of jet Reynolds number on the target surface, which is cooled from the opposite side. Agrawal et al [8] studied the effect of impinging turbulent flames on inclined surfaces and found that with a decrease in the oblique angle the heat flux distribution in the lower part of the plate increases but in the uphill part it is slightly dependent on of the oblique angle. The effect of convex curvature on heat transfer characteristic from an axi-symmetric jet is studied by Lee et al [9]. They found that the Nusselt number at the stagnation point increases with $d / D$. Tripathy et al [10] investigated theoretically diffusion as well as premixed turbulent flames impinging normally and obliquely on plane surfaces and found that average Nusselt number over the plate increases with an increase in $R e$ and equivalence ratio $(E R)$ and a decrease in $H / d$ for both the flames. Remie et al [11] derived analytically the laminar flame impingement heat transfer on target plate and observed that the heal flux depends on the distance of the target plate from the nozzle. Hindasageri et al [12] studied experimentally and numerically the heat transfer phenomena on a flat target plate using perforated burner flames. Wei et al [13] experimentally investigated the impingement of laminar premixed biogas flame and found that with increase in velocity of unburnt gas the heat flux as well as the total rate of heat transfer increases significantly. Singh et al [14] investigated experimentally the heat transfer properties of compressed natural gas and presented the distribution of radial temperature of flames at different axial heights and for different operating conditions.

A number of experiments were conducted by Dong et al [15] to calculate heat transfer properties of premixed flame (butane-air) on an inclined flat surface at various incident angles with respect to the plate. Nayak et al [16, 17] investigated natural convection heat transfer from heated vertical pipes experimentally and developed correlations for Nusselt number and Rayleigh number. Sahoo et al $[18,19]$ studied numerically the heat transfer from an isothermal plate with protrusions and developed correlations to predict the average Nusselt number as a function of fin spacing in the streamwise and spanwise directions, aspect ratio and inclination of the fins. Chaware and Sewatkar [20] analysed numerically the fluid flow and heat transfer in a pipe with full length twisted tape insert and developed correlations for friction factor and Nusselt number. Reza et al [21] studied theoretically the impingement of a lighter incompressible viscoelastic fluid orthogonally on the surface of another heavier incompressible viscous fluid in the region very close to the stagnation point and observed that interface temperature increases with increase in the viscoelastic parameter of the upper fluid.

\section{Numerical solution}

In the present work, finite-volume technique is used to solve the conservation equations of mass and momentum, energy, turbulent kinetic energy, dissipation rate of turbulent kinetic energy and species conservation equations.

The following assumptions have been made in this study:

1. The flow is turbulent but steady (based on time mean values of flow parameters).

2. The irreversible two-step global reaction is considered for oxidation of methane.

3. The gas phase comprising air and products of combustion is assumed to obey the ideal gas laws.

4. Flow at the outlet of the nozzle is considered to be uniform. 
5. The system is considered to be a grey body with respect to radiation characteristics.

\section{Governing equations}

With all these assumptions the governing equations are given as follows.

Conservation of mass:

$$
\nabla \cdot(\rho \vec{v})=0 .
$$

\section{Conservation of momentum:}

$$
\rho \vec{v} \cdot \nabla \vec{v}=-\nabla p+\nabla \cdot\left(\mu_{e f f} \nabla \vec{v}\right)+\vec{F}_{B}
$$

where $\mu_{\text {eff }}=\mu+\mu_{t}=\mu+\rho c_{\mu} \frac{k^{2}}{\varepsilon}$.

Here $\mu, \mu_{t}$ and $\mu_{\text {eff }}$ are laminar, turbulent and effective viscosity, respectively. $\vec{F}_{B}$ is the gravitational body force. Turbulent kinetic energy:

$$
\nabla \cdot(\rho \vec{v} k)=\nabla \cdot\left(\frac{\mu_{t}}{\sigma_{k}} \nabla k\right)+G_{k}-\rho \varepsilon .
$$

Rate of dissipation of turbulent kinetic energy:

$$
\nabla \cdot(\rho \vec{v} \varepsilon)=\nabla \cdot\left(\frac{\mu_{t}}{\sigma_{\varepsilon}} \nabla \varepsilon\right)+C_{1 \varepsilon} \frac{\varepsilon}{k} G_{k}-\rho C_{2 \varepsilon} \frac{\varepsilon^{2}}{k}
$$

where $k, \varepsilon$ and $G_{k}$ are the turbulent kinetic energy, dissipation rate of turbulent kinetic energy and generation of turbulent kinetic energy, respectively.

The values of constants are taken as

$$
\begin{aligned}
C_{\mu} & =0.0845, C_{1 \varepsilon}=1.42, \sigma_{k}=\sigma_{\varepsilon}=0.7194, C_{2 \varepsilon} \\
& =1.68+\frac{C_{\mu} n^{3}(1-(n / 4.8))}{1+0.012 n^{3}}
\end{aligned}
$$

where $n$ is the ratio of turbulence to the mean strain time scale.

Conservation of energy:

$$
\nabla \cdot(\rho \vec{v} h)=\nabla \cdot\left(\rho \alpha_{e f f} \nabla h\right)-\nabla \cdot \vec{q}^{r}
$$

where $h=\sum_{k=1}^{N} Y_{k}\left[h_{f, k}^{0}+\int_{T_{\text {ref }}}^{T} c_{p, k} d T\right]$.

Here, $h$ is the enthalpy of the mixture, $h_{f}^{0}$ is the enthalpy of formation and $\alpha_{\text {eff }}$ is the effective thermal diffusivity.

Species conservation:

$$
\nabla \cdot\left(\rho \vec{v} Y_{k}\right)=\nabla \cdot\left(\rho D_{\text {eff }} \nabla Y\right)+S_{k} .
$$

\section{Chemical kinetics:}

The equations for oxidation of methane are given by

$$
\begin{gathered}
\mathrm{CH}_{4}+1.5 \mathrm{O}_{2}=\mathrm{CO}+2 \mathrm{H}_{2} \mathrm{O}, \\
\mathrm{CO}+0.5 \mathrm{O}_{2}=\mathrm{CO}_{2} .
\end{gathered}
$$

The rate of reaction is given by Magnussen and Hjertager [22], as given here.
Arrhenius equation:

$$
\dot{\omega}_{f k}=B(\rho)^{a+b} \frac{Y_{f}^{a} Y_{o}^{b}}{M_{f}^{a} M_{o}^{b}} \exp \left(-\frac{E}{\bar{R} T}\right) .
$$

Magnussen and Hjertager equation:

$$
\dot{\omega}_{f d}=A \frac{\rho}{M_{f}} \frac{\varepsilon}{k}\left[\min \left(Y_{f}, \frac{Y_{o}}{\gamma}, \frac{c Y_{P}}{1+\gamma}\right)\right]
$$

where $M$ and $\gamma$ are the molecular weight and stoichiometric ratio, respectively.

Heat transfer coefficients at target plate:

Average heat transfer coefficient is given by

$$
\bar{h}=\frac{1}{A} \text { inthdA }
$$

and local heat transfer coefficient is given by

$$
h=\frac{q_{w}}{\left(T_{a d}-T_{w}\right)}
$$

where $T_{a d}$ and $T_{w}$ are the adiabatic flame temperature and wall temperature, respectively.

The wall heat flux $q_{w}$ is written as

$$
q_{w}=-k\left(\frac{\partial T}{\partial z}\right)_{\text {plate }}+q_{r w}
$$

where $q_{r w}$ is the heat flux due to radiation at the target surface.

The heat transfer to the plate is given by

$$
Q=\int q_{w} d A .
$$

The average Nusselt number $\bar{N} u$ is given by

$$
\bar{N} u=\frac{\bar{h}(2 R)}{k} .
$$

Boundary conditions and operating parameters:

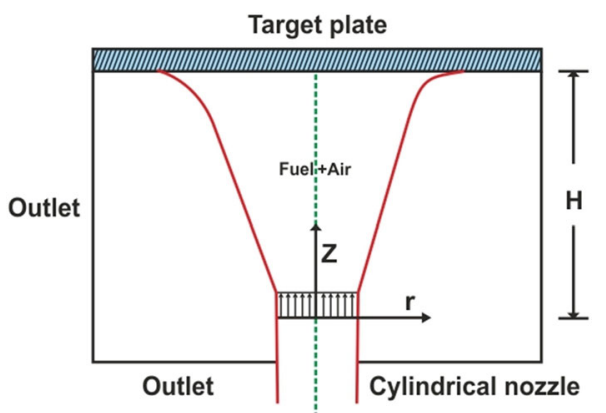

Figure 2. Methane-air-premixed flames impinging normally on plane surfaces. 
Axi-symmetric boundary condition is considered along the jet axis. Therefore, $r-z$ computational domain is taken as shown in figure 2.

For the numerical calculations, methane-air-premixed flame is considered. A burner diameter of $12 \mathrm{~mm}$ is taken. The temperature of both fuel and air at exit plane of the burner is taken as $300 \mathrm{~K}$. The distance of target plate from the burner and the flow rates are changed to get the following dimensionless parameters.

(i) Reynolds number $R e=\frac{\rho v_{i} d}{\mu}: 2000,4000,6000,8000$, 10000, 15000.

(ii) Equivalence ratio $E R=\frac{\left(Y_{a} / Y_{f}\right)_{s}}{\left(Y_{a} / Y_{f}\right)_{a}}: 0.8,1,1.2,2$.

Here, subscripts $s$ and $a$ denote stoichiometric air fuel ratio and actual air fuel ratio of the mixture, respectively.

(iii) The ratio of the separation distance to the nozzle diameter: $H / d=4,8,12$.

\subsection{Solution procedure}

The conservation equations were solved by employing a fully time implicit finite-volume technique using ANSYS Fluent software. The coupling between pressure and velocity was achieved by employing SIMPLE algorithm. The convergence criterion for the scaled residuals in all the discretized equations was set to $10^{-6}$. Typically, 150 $(r) \times 60 \quad(z)$ grid systems were chosen to discretize the domain for the $H / d$ ratio of $4: 1$. Similarly the grid size of $200 \times 180$ is selected along radial and axial directions, respectively, for $H / d=8$ and the grid size of $250 \times 320$ is selected along radial and axial directions, respectively, for $H / d=12$. An optimal size of the mesh was determined from several numerical calculations and it was observed that further refinement had negligible effect on the results.

It is assumed that the axial velocity distribution for fuelair mixture at the exit of the nozzle is uniform. No slip, no penetrating and isothermal conditions are assigned on target plate. The boundary condition at the exit plane of the computational domain is taken as outflow. Symmetric boundary condition is employed at the jet axis.

\section{Results and discussion}

In the present model, an isothermal target plate of specified temperature is considered. The result of the present model is compared to those of an experimental work by Van der Meer [23] as shown in table 1. A fair agreement is observed between the experimental work and the present model.

Grid independence study was conducted to find out the optimum grid size and it was observed that further refinement had negligible effect on the results. Table 2 shows the variation of average Nusselt number as a function of number of cells for various values of $H / d$ and for $R e=6000$.

Figure 3 shows the variation of average Nusselt number with grid size for various values of $H / d$. It is evident from table 2 and figure 3 that for $H / d=4$, as the number of cells in the domain increases from 3000 to 9000, average Nusselt number changes from 96.204 to 124.125 . Further increase in number of grids up to 20000 has negligible effect on the average Nusselt number.

Similarly, for $H / d=8$, as the number of cells in the domain increases from 12000 to 36000, average Nusselt number changes from 92.634 to 121.403 . Further increase in number of grids up to 80000 has negligible effect on the average Nusselt number. And for $H / d=12$, as the number of cells in the domain increases from 27000 to 81000 , average Nusselt number changes from 72.315 to 91.236. Further increase in number of grids up to 140000 has almost no effect or negligible effect on average Nusselt number. Therefore, considering both the accuracy of results and computational time, the optimum number of grids taken for the simulation is 9000,36000 and 81000 for the non-dimensional separation distances of 4,8 and 12 , respectively.

Figure 4 shows the local heat flux allocation at the target plate for $R e=6000$ and $E R=1$ with different values of separation distance of $H / d=4,8$ and 12 . It is found that a little further away from the stagnation point, heat flow from the surface reaches a maximum value and then gradually decreases as the radial distance from the centre of the plate is increased. It is evident from figures 6,7 and 8 that the flame temperature is maximum in the region close to the stagnation point and decreases gradually as the distance from the centre of the plate increases. Higher magnitude of local heat fluxes are caused by higher value of local temperature differences, which is clearly depicted by figures 6 and 7. Accordingly the heat transfer from the flame to the plate decreases as we go farther away from the centre of the plate, which is in accordance with the lower value of local temperature difference. At $R e=6000$, the flame is expected to be a fully developed turbulent one. When the target plate is relatively closer to the burner with the separation distance being less than the flame length, the flame gets deflected in the radial direction with spreading of reaction zone on the plate. The peak in plate heat flux distribution comes closer to the stagnation point with an increase in the value of $H / d$. This is due to the fact that as the separation distance increases there is complete combustion of the fuel before it reaches the target plate. As a result of this, there is maximum heat transfer from the flame to the plate near the stagnation point. Heat flux gradually improves for a decrease in the value of $H / d$ from 12 to 8 , and decreases near the stagnation region with further decrease in $H / d$ from 8 to 4.

For $H / d=4$, the heat flux near the stagnation region, including the peak heat flux, is lower as compared with that 
Table 1. Comparison of present theoretical predictions to experimental work [23].

\begin{tabular}{lccc}
\hline Fixed input parameters & $\begin{array}{c}\text { Variable parameters for both experimental (23) } \\
\text { and present model }\end{array}$ & Nu (at stagnation point) \\
\hline Fuel: & $H / d$ & Experimental results [23] & Theoretical predictions \\
Methane & 2 & 68.25 & 60.20 \\
Premixed flame & 4 & 112.10 & 103.25 \\
$E R=1.0$ & 6 & 116.50 & 108.40 \\
$R e=4226$ & 8 & 107.90 & 97.30 \\
\hline
\end{tabular}

Table 2. Average Nusselt number as a function of number of cells.

\begin{tabular}{|c|c|c|c|c|c|c|}
\hline \multirow[b]{2}{*}{ S1. no. } & \multicolumn{2}{|c|}{$H / d=4$} & \multicolumn{2}{|c|}{$H / d=8$} & \multicolumn{2}{|c|}{$H / d=12$} \\
\hline & No. of grids & $N u$ & No. of grids & $\mathrm{Nu}$ & No. of grids & $\mathrm{Nu}$ \\
\hline 1 & 3000 & 96.205 & 12000 & 92.634 & 27000 & 72.315 \\
\hline 2 & 4800 & 130.518 & 19200 & 127.703 & 43200 & 98.123 \\
\hline 3 & 7000 & 126.316 & 28000 & 123.214 & 63000 & 93.402 \\
\hline 4 & 9000 & 124.125 & 36000 & 121.403 & 81000 & 91.236 \\
\hline 5 & 12600 & 123.309 & 50400 & 120.626 & 113400 & 90.445 \\
\hline 6 & 20000 & 122.934 & 80000 & 119.916 & 140000 & 89.762 \\
\hline
\end{tabular}

for $H / d=8$. For higher values of $r / d$, the plate heat flux marginally increases when the non-dimensional separation distance changes from 4 to 8 .

The distributions of average Nusselt number $\bar{N} u$ over the plate with Reynolds number for various values of $H / d$ are shown in figure 5. It can be seen that with an increase in Reynolds number $R e$, average Nusselt number increases. It is also observed from figure 5 that the total heat flux from the plate for $H / d=4$ is more than that for $H / d=8$ up to a Reynolds number of 10000 , beyond which the trend is reversed. The reason for this may be due to the variations of typical flame shape and the resulting heat flux distribution at the plate surface for various values of $R e$ and $H / d$. When $H / d=4$, the plate is close to the burner and the flame is mostly attached to the plate at all Reynolds numbers. In this situation, it brings about a greater convective effect, reducing both the hydrodynamic and thermal boundary layer for flow of hot gases past the plate surface. This results in an increase in the rate of heat transfer. When the plate is kept at a larger distance from the burner, the flame is usually attached to nozzle rim. With an increase in $R e$, the flame length gets increased and the high-temperature reaction zone comes closer to the plate, resulting in an enhanced overall heat transfer.

For both $H / d=4$ and 8 , the flame looks like an annular flame having cool central core as shown in figures 6 and 7 . This core extends up to a distance very close to plate surface for $H / d=4$. This results in a relatively-high-temperature zone in stagnation region adjacent to the plate surface for $H / d=8$. In case of $H / d=12$, the flame looks almost like a nozzle-stabilized envelop flame due to the presence of the target plate (figure 8). This is ascribed to the radial spreading of flame and it is so shaped due to the interference of the target plate. Under this situation, there exists a short unreacted burner-attached cool conical core, which is surrounded by a high-temperature flame zone that extends almost up to the plate surface. For higher values of $H / d$, the temperature of the flame is reduced due to the entrapment of more air from the surrounding.

It is found that the qualitative trend of plate heat flux distribution at a higher value of $R e=10000$ (figure 9) is the same as that at $R e=6000$, but with a difference that the heat flux in stagnation region for $H / d=12$ is relatively increased, with the peak value being close to that for $H$ / $d=8$. This can be ascribed to the fact that there is an increase in flame length with increase in Reynolds number.

Figures 10-12 show the heat flux distributions at the plate for various values of separation distance $H / d$ and equivalence ratio $E R$. It is found that local heat flux at any radial location of the plate for all values of $H / d$ is slightly increased with an increase in $E R$.

It is interesting to note that for a highly-fuel-rich mixture $(E R=2)$, the plate heat flux for $H / d=12$ increases substantially with the peak value being close to that for $H /$ $d=8$ (figure 12). This can be explained due to the fact that for a rich mixture, the air diffusing from surrounding atmosphere produces a stoichiometric fuel-air mixture, resulting in an external diffusion flame that is very close to the surface of the plate at a large separation distance.

Figure 13 depicts the variation of average Nusselt number $\bar{N} u$ over the plate with Reynolds number for various 


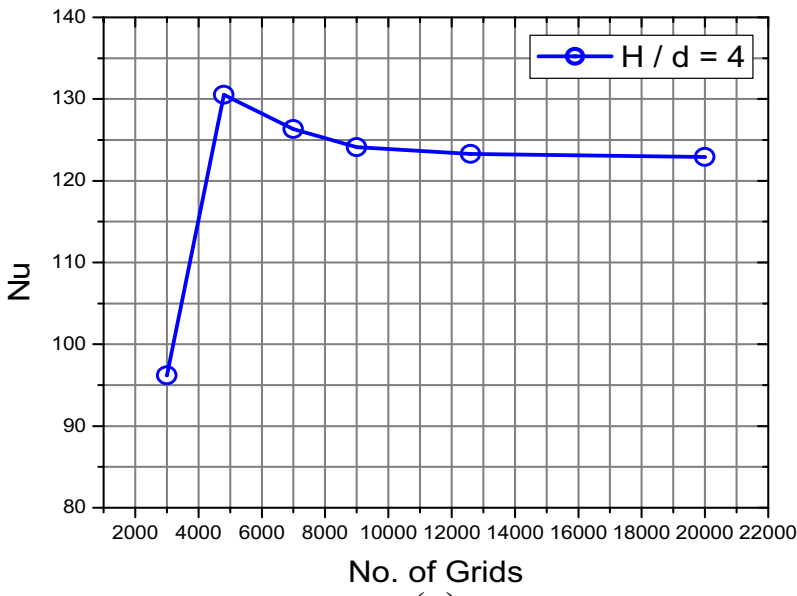

(a)

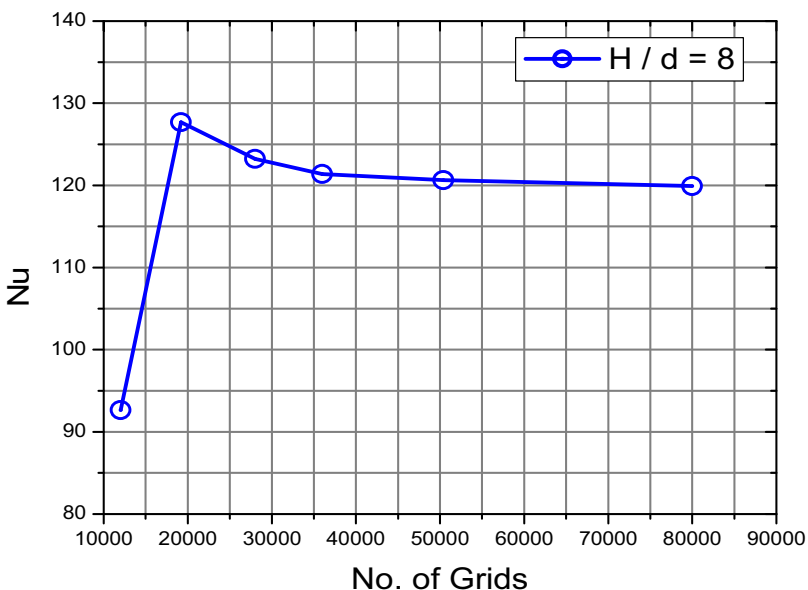

(b)

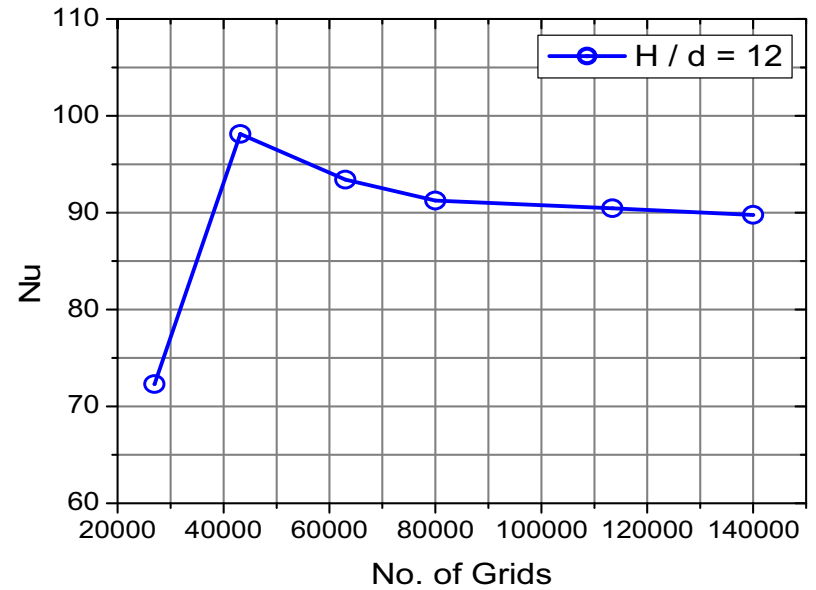

(c)

Figure 3. Average Nusselt number as a function of grid size for (a) $H / d=4$, (b) $H / d=8$ and (c) $H / d=12$.

$E R$. It is evident that with an increase in Reynolds number $R e$, average Nusselt number increases for all values of $E R$. As $E R$ increases, the total heat flux also increases for all values of Reynolds number $R e$. An improvement in average heat flux to the plate with increase in Reynolds number can

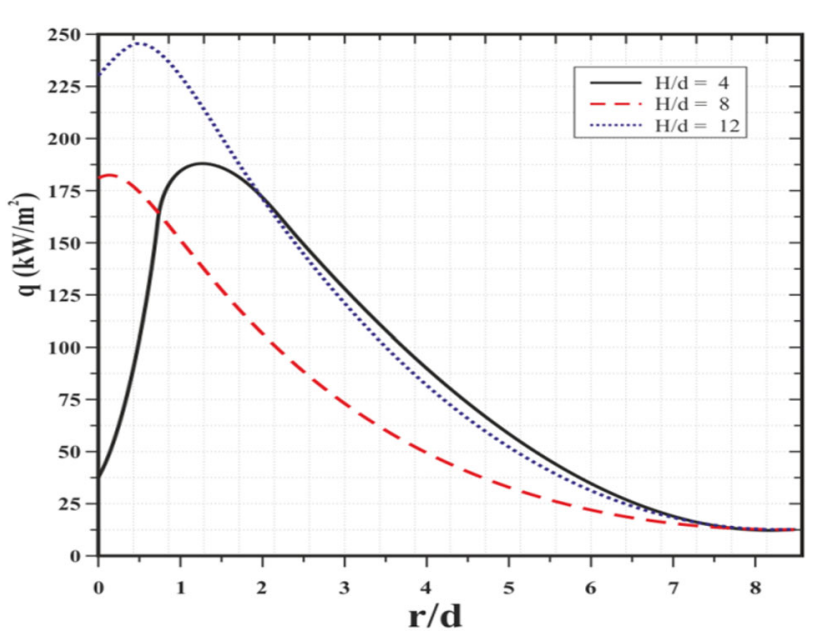

Figure 4. Radial distribution of local heat flux for various plate separation distances $(R e=6000$ and $E R=1)$.

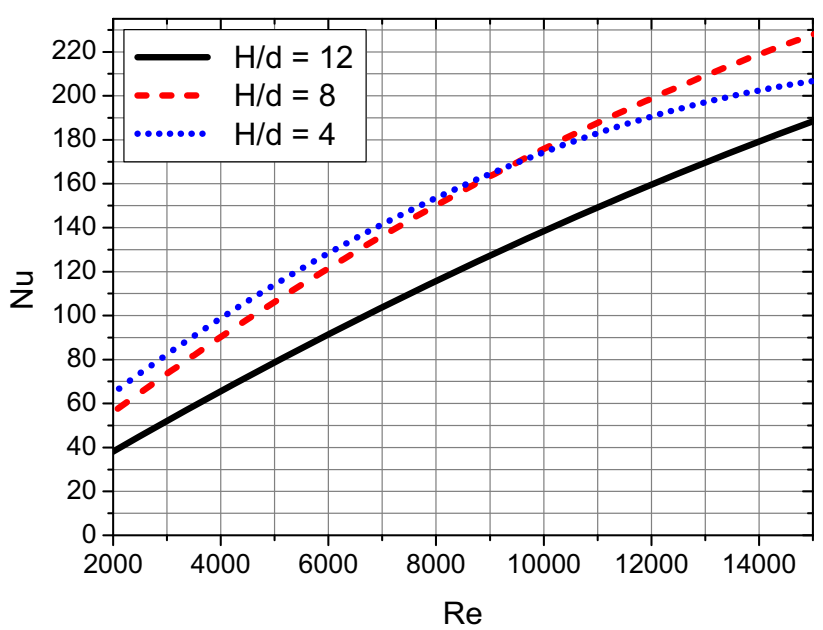

Figure 5. Variations of $\bar{N} u$ with $R e$ and $H / d$ in premixed flames $(E R=1)$.

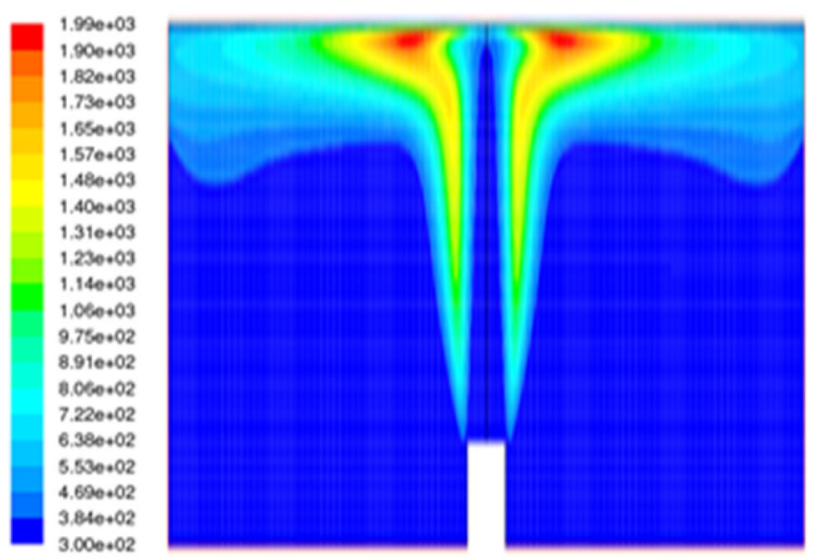

Figure 6. Temperature profile for premixed flames $H / d=4$, $E R=1, R e=6000$ (temperature is in $\mathrm{K}$ ). 


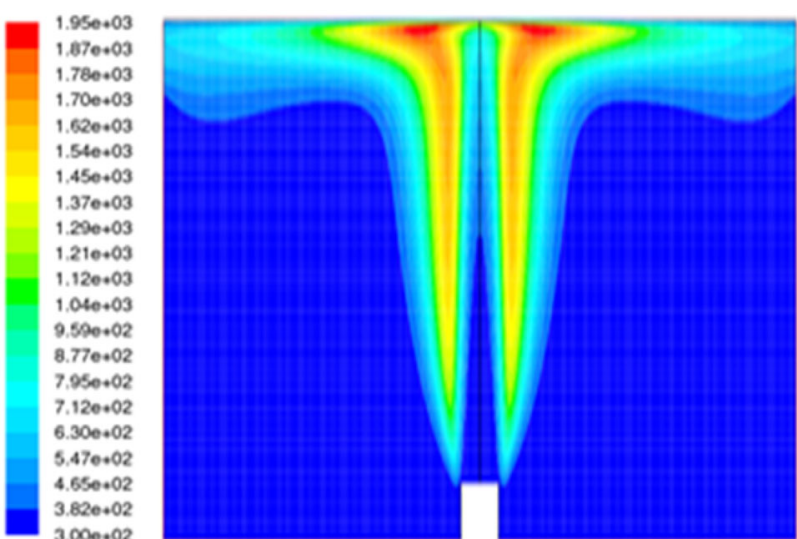

Figure 7. Temperature profile for premixed flames $H / d=8$, $E R=1, R e=6000$ (temperature is in $\mathrm{K}$ ).

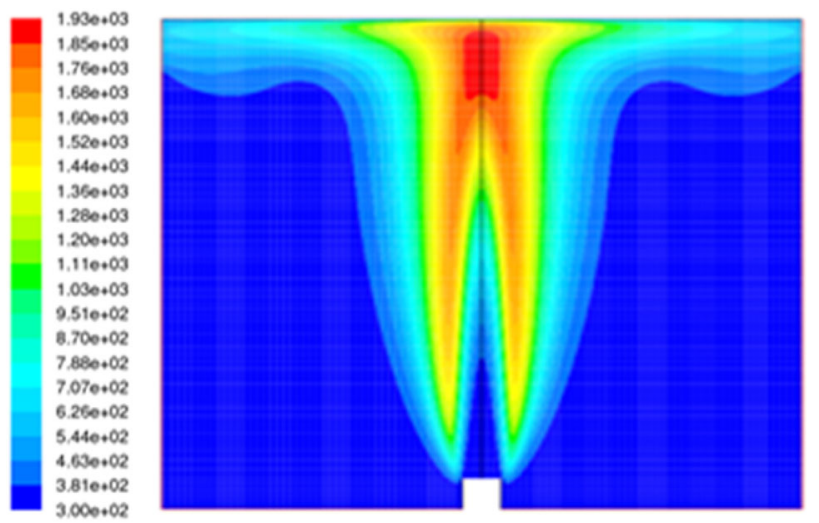

Figure 8. Temperature profile for premixed flames $H / d=12$, $E R=1, R e=6000$ (temperature is in $\mathrm{K}$ ).

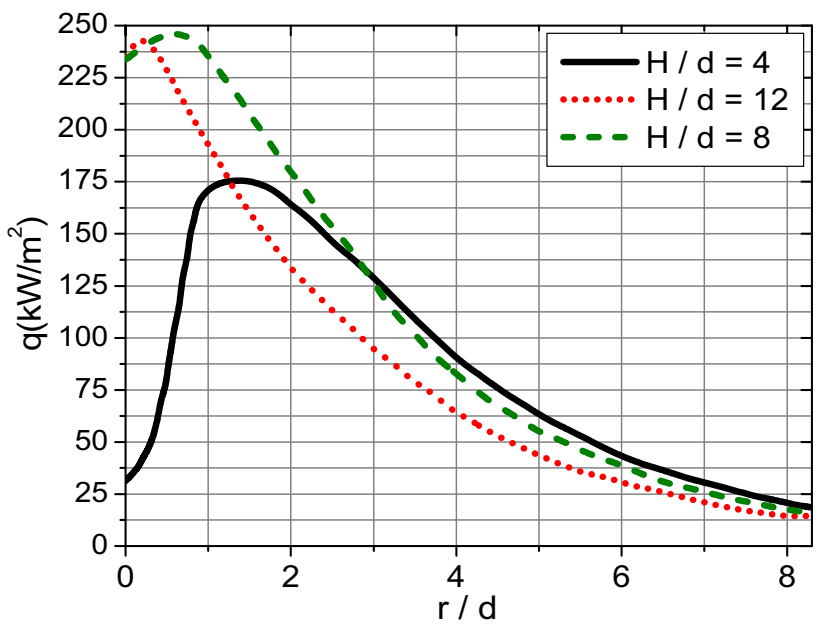

Figure 9. Radial distribution of local heat flux for various plate separation distances $(R e=10000$ and $E R=1)$.

be endorsed to the fact that with increase in Reynolds number, the length of flame increases, as a result of which the inner high-temperature reaction zone comes nearer to

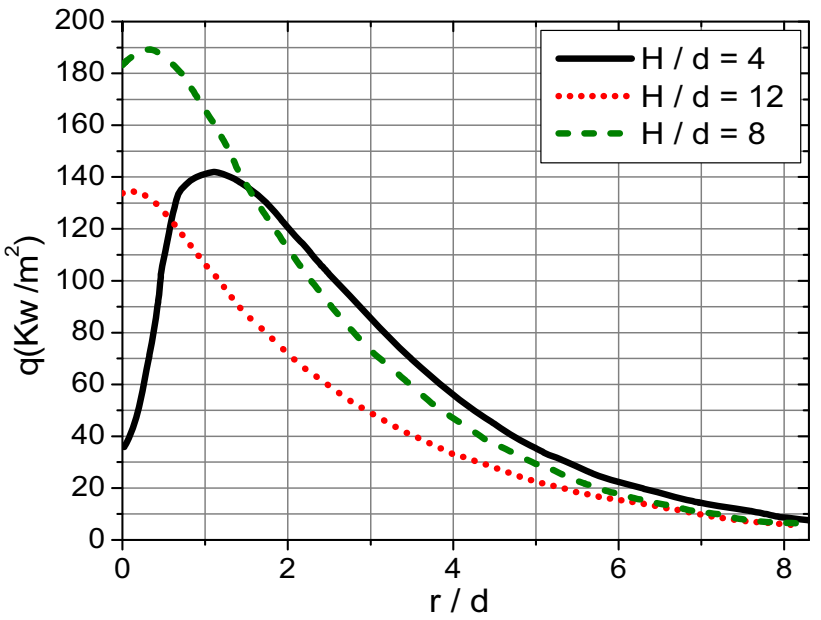

Figure 10. Radial distribution of local heat flux for various plate separation distance $(E R=0.8$ and $R e=6000)$.

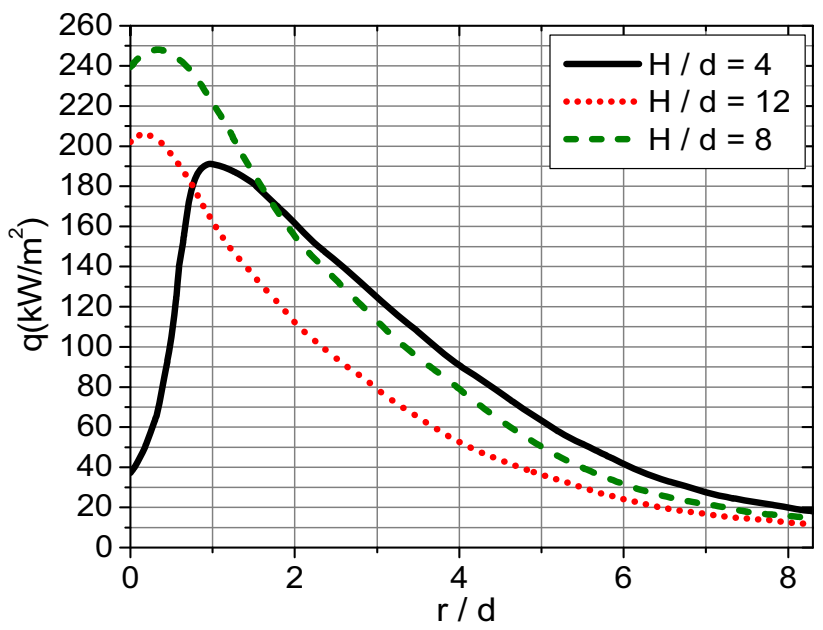

Figure 11. Radial distribution of local heat flux for various plate separation distances $(E R=1.2$ and $R e=6000)$.

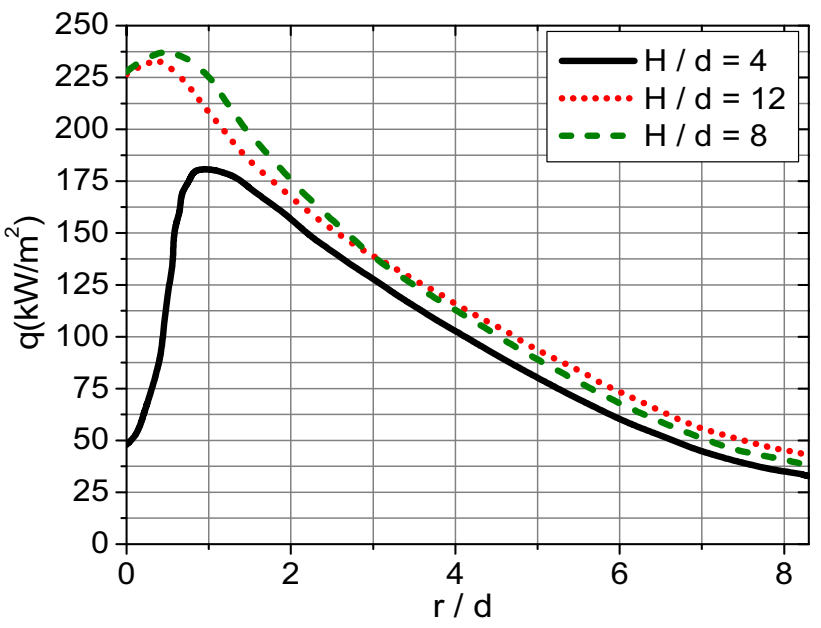

Figure 12. Radial distribution of local heat flux for various plate separation distances $(E R=2$ and $R e=6000)$. 


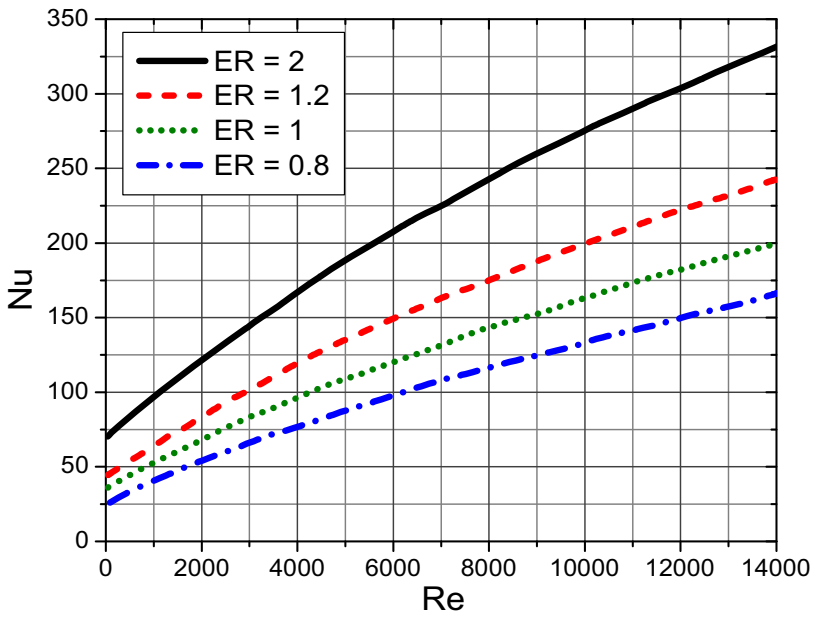

Figure 13. Variation of $\bar{N} u$ with $R e$ for various values of $E R$ at $H / d=8$

target plate. In addition the high-temperature reaction zone shifts radially outward, surrounding the plate from the stagnation point with an increase in $R e$. Moreover, this is also due to the fact that with increase in Reynolds number, the convective heat transfer increases, which results from higher velocities. When the value of $H / d$ decreases, the hot inner reaction zone comes closer to the plate with spreading of flame in the radial direction, as a result of which there is an increase in heat flux to the plate. Similarly, with increase in ER from 0.8 up to 2, the mixture becomes rich in fuel. Hence, the flame temperature as well as the heat transfer to the plate increases. The increase of heat flux is more prominent at higher values of $R e$ and for $E R=2$. This is attributed to the fact that for fuel-rich premixed jets, due to the diffusion of air from the surrounding atmosphere, a combustible stoichiometric air-fuel mixture is created near the surface of the plate, resulting in an external diffusion flame near the plate at a large separation distance.

\section{Conclusions}

The following conclusions are drawn from this numerical study:

- The heat flux from the surface of the plate reaches a maximum value at a location slightly away from stagnation point and then decreases with increase in radial distance from the centre of the plate.

- The location of the maximum value of the local heat flux approaches the stagnation point as the separation distance of the target plate from the nozzle increases.

- The maximum value of heat flux near the stagnation region gradually increases when the value of $H / d$ decreases from 12 to 8 . As $H / d$ further reduces from 8 to 4 , the maximum value of heat flux decreases near the stagnation point.
- As the Reynolds number $R e$ and $E R$ increase, the average Nusselt number $\bar{N} u$ increases.

\section{Nomenclature}

$C_{p} \quad$ specific heat at constant pressure $(\mathrm{kJ} / \mathrm{kg} \mathrm{K})$

$D$ diffusion coefficient $\left(\mathrm{m}^{2} / \mathrm{s}\right)$

$d$ burner diameter (m)

$H$ distance of the target plate from the nozzle (m)

$h \quad$ specific enthalpy $(\mathrm{kJ} / \mathrm{kg})$

I radiation intensity $\left(\mathrm{kW} / \mathrm{m}^{2}\right)$

$K$ thermal conductivity of the plate $(\mathrm{kW} / \mathrm{m} \mathrm{K})$

$\mathrm{Nu}$ Nusselt number

$p$ pressure $(\mathrm{Pa})$

$q$ heat flux $\left(\mathrm{kW} / \mathrm{m}^{2}\right)$

$R \quad$ universal gas constant $(\mathrm{J} / \mathrm{mol} \mathrm{K})$

$R e$ Reynolds number

$R \quad$ plate radius $(\mathrm{m})$

$r$ burner radius $(\mathrm{m})$

$T$ absolute temperature (K)

\section{Greek symbols}

$\alpha$ thermal diffusivity $\left(\mathrm{m}^{2} / \mathrm{s}\right)$

$\mu_{t} \quad$ turbulent viscosity $(\mathrm{kg} / \mathrm{m} \mathrm{s})$

$\gamma \quad$ stoichiometric air fuel ratio

$\mu$ dynamic viscosity $(\mathrm{kg} / \mathrm{m} \mathrm{s})$

$k$ turbulent kinetic energy $\left(\mathrm{m}^{2} / \mathrm{s}^{2}\right)$

$\varepsilon \quad$ dissipation rate of turbulent kinetic energy $\left(\mathrm{m}^{2} / \mathrm{s}^{3}\right)$

$\rho$ density $\left(\mathrm{kg} / \mathrm{m}^{3}\right)$

\section{References}

[1] Baukal C E and Gebhart B 1996 A review of empirical flame impingement heat transfer correlations. International Journal of Heat and Fluid Flow 17: 386-396

[2] Boke Y E, Aydin O and Yildizay H D 2011 The comparison of experimental and predicted flame temperature of natural gas combustion. Energy Sources, Part A: Recovery, Utilization, and Environmental Effects 33: 1271-1280

[3] Chander S and Ray A 2007 Heat transfer characteristics of laminar methane/air flame impinging normal to a cylindrical surface. Experimental Thermal and Fluid Science 32: 707-721

[4] Cornaro C, Fleischer A S, Rounds M and Goldstein R J 2001 Jet impingement cooling of convex semi-cylindrical surface. International Journal of Thermal Science 40: 890-898

[5] Dong L L, Cheung C S and Leung C W 2002 Heat transfer from an impinging premixed butane/air slot flame jet. International Journal of Heat and Mass Transfer 45: 979-992

[6] Hou S S and Ko Y C 2005 Influence of oblique angle and heating height on flame structure temperature field and 
efficiency of an impinging laminar jet flame. Energy Conversion and Management 46: 941-958

[7] Kuntikana P and Prabhu S V 2016 Isothermal air jet and premixed flame jet impingement heat transfer characterization and comparison. International Journal of Thermal Sciences 100: 401-415

[8] Agrawal G K, Chakraborty S and Som S K 2010 Heat transfer characteristics of premixed flame impinging upwards to plane surfaces inclined with the flame jet axis. International Journal of Heat and Mass Transfer 53: 1899-1907

[9] Lee H, Chung Y S and Kim D S 1997 Turbulent flow and heat transfer measurement on curved surface with fully developed round impinging jet. International Journal of Heat and Fluid Flow 18: 160-169

[10] Tripathy S, Rout A K and Roul M K 2016 Heat Transfer due to impinging flame on plane surface. IOSR Journal of Mechanical and Civil Engineering 13: 27-34

[11] Remie M J, Cremers M F G, Schreel K R A M and de Goey L P H 2007 Analysis of the heat transfer of an impinging laminar flame jet. International Journal of Heat and Mass Transfer 50: 2816-2827

[12] Hindasageri V, Kuntikana P, Vedula R P and Prabhu S V 2015 An experimental and numerical investigation of heat transfer distribution of perforated plate burner flames impinging on a flat plate. International Journal of Thermal Sciences 94: 156-169

[13] Wei Z L, Zhen H S, Leung C W, Cheung C S and Huang Z H 2015 Heat transfer characteristics and the optimized heating distance of laminar premixed biogas hydrogen Bunsen flame impinging on a flat surface. International Journal of Hydrogen Energy 40: 15723-15731

[14] Singh G, Chander S and Ray A 2012 Heat transfer characteristics of natural gas/air swirling flame impinging on a flat surface. Experimental Thermal and Fluid Science 41: 165-176
[15] Dong L L, Leung C W and Cheung C S 2002 Heat transfer characteristics of premixed butane/air flame jet impinging on an inclined flat surface. Heat and Mass Transfer 39: 19-26

[16] Nayak R C, Roul M K and Sarangi S K 2017 Experimental investigation of natural convection heat transfer in heated vertical tubes with discrete rings. Experimental Techniques 41: 585-603

[17] Nayak R C, Roul M K and Sarangi S K 2018 Natural convection heat transfer in heated vertical tubes with internal rings. Archives of Thermodynamics 39(4): 85-111

[18] Sahoo L K, Roul M K and Swain R K 2017 Natural convection heat transfer augmentation factor with square conductive pin fin arrays. Journal of Applied Mechanics and Technical Physics 58: 1115-1122

[19] Sahoo L K, Roul M K and Swain R K 2018 CFD analysis of natural convection heat transfer augmentation from square conductive horizontal and inclined pin fin arrays. International Journal of Ambient Energy 39: 840-851

[20] Chaware P and Sewatkar C M 2018 Effects of tangential and radial velocity on fluid flow and heat transfer for flow through a pipe with twisted tape insert-laminar flow. Sadhana 43: 150

[21] Reza M, Panigrahi S and Mishra A K 2017 Stagnation point flow and heat transfer for a viscoelastic fluid impinging on a quiescent fluid. Sadhana 42: 1979-1986.

[22] Magnussen B F and Hjertager B H 1976 On mathematical models of turbulent combustion with special emphasis on soot formation and combustion. In: Proceedings of the 16th Symposium (International) on Combustion, The Combustion Institute, Pittsburgh, PA: 719-729

[23] Van der Meer T H 1991 Stagnation point heat transfer from turbulent low Reynolds number jets and flame jets. Experimental Thermal and Fluid Science 4: 115-126 